Asian-American and European-American Emerging Adults’ Perceived Parenting Styles and Self-Regulation Ability

By Shen, J. J., Cheah, C. S. L., \& Yu, J.

"CAmerican Psychological Association, 2018. This paper is not the copy of record and may not exactly replicate the authoritative document published in the APA journal. Please do not copy or cite without author's permission. The final article is available, upon publication, at: http://dx.doi.org/10.1037/aap0000099" 


\begin{abstract}
Self-regulation refers to one's ability to manage one's emotions and behaviors in response to situational demands, and is an important ability during emerging adulthood. Parenting styles play a significant role in children's self-regulation development. Differences in the levels of parenting styles (authoritative and authoritarian styles) and self-regulation abilities between AsianAmericans (AA) and European-Americans (EA) have been found. However, few studies have explored the associations between parenting styles and self-regulation among emerging adults across these two cultural groups. The present study compared 377 emerging adults (146 AA and $231 \mathrm{EA}, 71 \%$ female, $\left.M_{\text {age }}=20.19, S D_{a g e}=1.67\right)$ on their: $(1)$ perceptions of parents' parenting styles, (2) self-regulation ability, and (3) the associations between perceived parenting styles and self-regulation skills. Our moderated mediation analysis indicated that parenting styles explained the ethnic differences in emerging adults' self-regulation but ethnicity did not moderate the effects of parenting styles on self-regulation. Specifically, compared to their EA counterparts, AA emerging adults perceived receiving lower levels of authoritative parenting and higher levels of authoritarian parenting, which in turn predicted lower self-regulation abilities in AA versus EA emerging adults. However, for both AA and EA emerging adults, authoritative parenting was positively associated with self-regulation and authoritarian parenting was negatively associated with self-regulation.

Public Significance Statement

Parenting styles were similarly related to self-regulation for Asian-American and EuropeanAmerican emerging adults. Findings highlighted the importance of enhancing authoritative parenting and reducing authoritarian parenting to promote self-regulation competence in emerging adults.
\end{abstract}


Keywords: self-regulation, authoritative parenting, authoritarian parenting, emerging adults, ethnic differences 
Asian-American and European-American Emerging Adults’ Perceived Parenting Styles and SelfRegulation Ability

Self-regulation refers to an individual's ability to manage emotional and physical arousal and execute his or her behavior in response to contextual demands (Brown, 1998). Studies have found self-regulation to be an important predictor of a variety of developmental outcomes, including prosocial behavior and social competence (Bowers et al., 2011; Spinrad et al., 2006), academic achievement (Blair \& Diamond, 2008; McClelland \& Wanless, 2012), and psychological well-being (Wrosch, Scheier, Miller, Schulz, \& Carver, 2003). In contrast, selfregulation difficulties in childhood can lead to long-term negative consequences, such as lower educational attainment and more financial difficulties in adulthood (McClelland, Acock, Piccinin, Rhea, \& Stallings, 2013; Moffitt et al., 2011).

Advancements in neuroscience indicate that brain regions important for top-down selfregulation (i.e., effortful or executive control processes) continue to develop during adolescence (Petanjek, Judaš, Kostović, \& Uylings, 2008) and over the course of young adulthood (Steinberg, 2004). However, examinations of self-regulation during emerging adulthood, conceptualized as a distinctive developmental period between 18 to 25 years of age, is limited. Emerging adults are exploring a variety of life possibilities regarding career, interpersonal relationships, and worldviews before they take on adult roles (Arnett, 2000). Self-regulation is an important ability during emerging adulthood because individuals are making life choices that require autonomous regulation of their behavior and emotion. Examinations of emerging adults' self-regulation capabilities can reveal important processes related to commonly observed adjustment indices during this period, such as risk behavior (Bachman, Johnston, O’Malley, \& Schulenberg, 1996) and sensation seeking (Arnett, 1994). 
Previous research on children’s self-regulation development has identified parenting styles to be an important predictor (e.g., Grolnick \& Ryan, 1989; Patock-Peckham, Cheong, Balhorn, \& Nagoshi, 2001). Of particular interest to this study are authoritative and authoritarian parenting styles (Baumrind, 1971). In general, authoritative parenting has been found to be associated with higher levels of children's self-regulation (Grolnick \& Ryan, 1989; PatockPeckham et al., 2001). In contrast, authoritarian and controlling parenting appear to undermine children’s self-regulation development (Karreman, van Tuijl, van Aken, \& Deković, 2006).

Studies on parenting styles with multicultural samples have shown differences in the mean levels of these parenting styles, and that the effects of the same parenting style on children and adolescents’ development may vary across different cultural groups (e.g., Leung, Lau, \& Lam, 1998; Lindahl \& Malik, 1999). However, research on the associations between parenting styles and self-regulation skills during emerging adulthood is limited, particularly comparisons across different ethnic groups. Thus, the overall aim of this study was to examine and compare the associations between authoritative and authoritarian parenting styles and emerging adults’ self-regulatory skills across Asian-American and European-American emerging adults. In this study, self-regulation was defined as a person's generalized ability to formulate and implement a long-term plan or goals (Brown, 1998). Goal establishment and behavior execution towards the achievement of the goals are common components of self-regulation definitions in the literature (Zeidner, Boekaerts, \& Pintrich, 1999). These regulatory skills are pivotal during emerging adulthood when individuals are tasked with setting up personal goals, implementing their plans, and making adjustment to accomplish their various life goals. Thus, it is important to examine whether emerging adults’ self-regulation ability is shaped by their parenting experiences.

\section{Parenting Styles and Self-regulation}


Parenting styles characterize the overall emotional climate parents create within the family that is stable over time and across a broad range of situations (Collins, Maccoby, Steinberg, Hetherington \& Bornstein, 2000), and provides a context in which parenting behaviors are expressed (Darling \& Steinberg, 1993). During early childhood and adolescence, parenting practices and the family emotional climate have been found to influence children’s self-regulatory development (Eiden, Colder, Edwards, \& Leonard, 2009; Moilanen, Rasmussen, \& Padilla-Walker, 2015). Authoritative parents engage in positive control that is supportive, assertive, and directive (Baumrind, 1991). These parents specify guidelines, provide a rationale to the behaviors, and encourage their children to work through problems themselves, all of which foster the process of internalization of regulation (Grolnick \& Farkas, 2002; Putnam, Spritz, \& Stifter, 2002). In addition, authoritative parents often express high levels of warmth and responsiveness towards their children (Baumrind, 1971), which have been found to predict more effortful control (Eisenberg et al., 2005), higher self-regulation, and observed compliance in children (Kochanska \& Aksan 1995). Responsive parenting strategies also help children understand principles of cause and effect (Maccoby \& Martin, 1983), which may facilitate their motivation to meet situational demands (Grusec \& Goodnow, 1994).

In contrast, authoritarian parents engage in dominating control that is harsh, excessive, and intrusive, which has been shown to be associated with children's self-regulation difficulties (Karreman et al., 2006; Kochanska \& Knaack, 2003). For example, authoritarian parenting has been found to be associated with children’s lower effortful control (Zhou, Eisenberg, Wang, \& Reiser, 2004). Controlling parents do not fulfill their children’s need for autonomy, but instead undermine children’s propensity for volitional regulation (Niemiec et al., 2006; Vansteenkiste, Simons, Lens, Sheldon, \& Deci, 2004) and deprive children of opportunities to figure out self- 
regulatory strategies independently (Grolnick, McMenamy, Kurowski, 1999). In addition, authoritarian parents engage in low levels of communication, warmth, and acceptance (Baumrind, 1991), which does not fulfill individuals’ need for relatedness with their parents, and thus, hinder their internalization of rules and self-regulation development.

During emerging adulthood, individuals start to minimize their dependence on family but have not yet completely established independence (Arnett, 2000). Research on emerging adults has found that in the United States, the relationship of emerging adults with their parents can be described as a balance between searching for individual independence and returning to parents for support and comfort (O’Connor, Allen, Bell, \& Hauser, 1996). Thus, emerging adults’ perceptions of their parents' parenting style are important for their self-regulatory abilities. Due to the changing nature of emerging adults’ living situations (i.e., many are no longer living with parents) and their increasing developmental need for independence and autonomy, the family dynamic and function of parenting during this developmental stage may be different compared to younger ages (Nelson, Padilla-Walker, Christensen, Evans, \& Carroll, 2011). Therefore, current knowledge on the association between parenting styles and self-regulation during childhood and adolescence may vary during emerging adulthood and should be examined.

\section{The Role of Culture}

Cultural variations in the development of self-regulation has been proposed. Asian cultures generally favor interdependence and harmony that require the flexibility and adjustment of the self to fit with the social relationships in various situations, which differs primarily from Western cultures' view of self and its relation to the world (Trommsdorff, 2012). Accordingly, self-regulation in interdependent cultures primarily focuses on fitting in with the social group and maintaining interpersonal harmony, whereas the main self-regulating mechanisms in 
independent cultures are autonomy-focused and aim to change the situation or the environment (Trommsdorff, 2009, 2012).

Findings from the small number of studies that have compared self-regulation and related abilities between Asian-Americans and European-Americans are inconclusive. Some studies have focused on emotion regulation, which is a subcomponent of self-regulation that requires regulatory strategies to modulate emotional experience towards the implementation of long-term goals (Bridgett, Burt, Edwards, \& Dearter-Deckard, 2015). For example, Cheung and Park (2010) found that Asian-American college students self-reported significantly higher levels of anger suppression compared to European-Americans. However, Kitsantas, Winsler, and Huie (2008) did not find significant differences in self-regulatory strategies related to metacognitive skills and time management between Asian-Americans and European-Americans college students. These mixed findings may be explained by the different conceptualization of self-regulation in Asian and Western cultures. Self-regulatory skills emphasizing emotional control and regulation that help preserve group cohesion and harmony may be more valued and practiced among Asian cultures (Trommsdorff, 2012), which may lead Asian-American college students to score higher than their European-American peers. However, when self-regulation is defined and measured as metacognitive and time management strategies, the significance of these concepts may be equally embraced in Asian and Western cultures, thus, yielding fewer cultural variations. Given the inconclusive findings on self-regulation between Asian-American and European-American college students, further comparisons of the two cultural groups on this construct is needed. The present study is interested in understanding self-regulation as a generalized capacity to implement goal-directed behavior and delay gratification in the short term to achieve desired 
outcomes in the future (Neal \& Carey, 2005). Specifically, we explored potential self-regulatory differences among Asian-American and European-American emerging adults.

The rates of engagement in authoritative versus authoritarian parenting styles have also been found to differ between parents from Asian and Western cultural groups. Li, Costanzo and Putallaz (2010) reported that Chinese college students perceived their mothers to be more authoritarian compared to their European-American peers, although both groups reported the same levels of maternal authoritative style. Compared to European-American high school students, Asian-American students rated their parents as higher on the authoritarian style and lower on the authoritative style (Dornbusch, Ritter, Leiderman, Roberts, \& Fraleigh, 1987). Asian-American parents of adolescents were also more likely to manifest authoritarian decisionmaking than European-American parents (Pong, Hao, \& Gardner, 2005).

Cross-cultural research has also examined the associations between authoritative and authoritarian parenting styles and children’s social emotional outcomes in Asian and Western cultural groups. The positive impact of authoritative parenting on children's social adjustment is generally found cross-culturally, but the effect of authoritarian parenting on child social emotional adjustment across Asian and Western cultures is less conclusive. Some studies suggest cultural differences in the negative effect of authoritarian parenting on child development. For instance, contrary to the expected trend found in European-American adolescents, authoritarian parenting was positively related to Chinese students' school performance (Leung et al., 1998). Nevertheless, recent studies have demonstrated more similar effects of authoritarian parenting on individual development across cultures. Using nationally representative data from the United States and Taiwan, Pong, Johnston, and Chen (2010) found that the impact of parenting styles on school achievement among Taiwanese adolescents and European-American students were 
similar. Specifically, authoritative parenting was beneficial to adolescents’ academic performance, whereas authoritarian parenting was negatively associated with school performance for both Taiwanese and European-American students (Pong et al., 2010). Moreover, a recent meta-analysis across 428 studies found a universally positive association of authoritarian parenting style with internalizing and externalizing problems and a negative effect of authoritarian parenting on academic achievement in North America, Western Europe, Eastern Europe, East Asia, South Asia, and Arab-Muslim countries (Pinquart \& Kauser, 2017).

Studies examining the role of parenting in children's self-regulation conducted in the U.S. generally show a positive relation between the authoritative parenting style and children's selfregulatory skills and a negative association between the authoritarian parenting style and children’s self-regulation (e.g., Moilanen et al., 2015). Similarly, authoritative parenting positively predicted effortful control whereas authoritarian parenting, especially components such as corporal punishment and verbal hostility, negatively impacted mainland Chinese children's effortful control (Zhou et al., 2004). In addition, optimal self-regulation is the outcome of parental socialization which takes place as parents communicate to children the appropriate behavior and reaction based on the situational demands (Moilanen et al., 2015). Across cultures, authoritative parenting creates a warm and welcoming emotional atmosphere within the family, and this familial emotional climate may facilitate effective parental socialization of selfregulation. In contrast, hostile and authoritarian parenting style conveys to children a less accepting or supportive attitude from parents (Darling \& Steinberg, 1993). Thus, the socialization of self-regulation can be disruptive and ineffective among authoritarian parents across various cultures. Therefore, although mean-level differences in parenting style and selfregulation abilities likely exist between Asian-Americans and European-Americans, we expected 
that the link between parenting style and emerging adults' self-regulation would be similar across the two cultural groups.

\section{The Present Study}

Our understanding of associations between authoritative and authoritarian parenting styles and self-regulation among Asian-Americans versus European-Americans remains limited, especially during the period of emerging adulthood. Thus, in the present study, we applied both a level-oriented comparison, which examined differences in the magnitude of parenting and selfregulation across cultures (Van de Vijver \& Leung, 1997a, 1997b), and a structure-oriented comparison that explored the associations among the variables (Rossier, Dahourou, \& McCrae, 2005; Smith \& Bond, 2003). Specifically, we compared Asian-American and EuropeanAmerican emerging adults on the following: (1) their perceptions of their parents' engagement in authoritative and authoritarian parenting styles; (2) their self-reported self-regulation ability; and (3) the associations between their parents' authoritative and authoritarian parenting styles and their own self-regulation skills.

First, we hypothesized that compared to European-American emerging adults, AsianAmerican emerging adults would perceive receiving lower levels of authoritative parenting and higher levels of authoritarian parenting. Second, due to limited empirical evidence, no directional hypothesis was proposed regarding the difference in self-regulation between Asian-American and European-American emerging adults. Last, we hypothesized that, despite the mean differences in parenting styles, authoritative parenting would be associated with higher levels of self-regulation and authoritarian parenting would be associated with lower levels of selfregulation among both Asian-American and European-American emerging adults.

\section{Method}




\section{Participants}

The initial sample consisted of 401 participants with 248 European-American and 153 Asian-American college students. There were 24 participants (6\%) who did not finish one or more measures, and therefore were dropped from the final sample. The final data contained 377 students between the ages of 18 to 25 years $\left(71 \%\right.$ female, $M_{a g e}=20.19$, $\left.S D_{\text {age }}=1.67\right)$ attending university in a mid-Atlantic region of the United States. Based on self-reports, 146 of the participants identified as Asian-American (63\% U.S.-born; $n=92)$ and 231 identified as European-American (97\% U.S.-born; $n=224)$. The sample of Asian-Americans comprised individuals of East Asian ( $n=61$; Chinese, Korean, Japanese), Southeast Asian $(n=22$; Vietnamese, Thai, Filipino, and Cambodian), and South Asian ( $n=63$; Indian, Bangladeshi, Pakistani, and Sri Lankan) ethnic backgrounds. Participants were from 45 different majors, but the majority of them majored in psychology $(n=183$; 49\%) or the biological sciences $(n=80$; 21\%). The sample included similar numbers of freshmen $(27 \%, n=101)$, sophomores $(20 \%, n=$ 77), juniors (27.3, $n=103)$, and seniors $(26 \%, n=96)$.

Regarding their mothers’ highest level of education, the lowest level reported by AsianAmerican participants was 1 (less than $7^{\text {th }}$ grade) and the highest was 7 (graduate/professional degree $)(M=5.10, S D=1.45)$. For European-American participants, their mothers' highest level of education ranged from 4 (high school graduate or $G E D)$ to $7(M=5.79, S D=1.03)$. In terms of fathers' highest level of education, Asian-American students reported from 1 to 7 ( $M=5.43$, $S D=1.40)$, whereas the European-American students reported from $2\left(7^{\text {th }}, 8^{\text {th }}\right.$, or $9^{\text {th }}$ grade $)$ to 7 $(M=5.83, S D=1.17)$. Independent samples $t$-test showed that the European-American mothers and fathers had significantly higher average education levels than the Asian-American mothers and fathers, $t(373)=5.40, p<.001$, and, $t(371)=3.00, p<.005$, respectively. 


\section{Procedures}

Institutional review board (IRB) approval from the university was obtained before any data collection procedure. Participants were recruited through the Psychology Subject Pool from the investigators’ university’s psychology department. In addition, recruitment flyers were posted throughout the campus to access a more diverse sample in terms of majors and ethnicities. Students were informed that they would need to complete online questionnaires regarding their perceptions of their parents and themselves. Students who showed an interest in participating were provided a link to complete an online survey created on Qualtrics. Before starting the survey, students provided electronic consent through Qualtrics, and were informed that withdrawal at any point of the study would not lead to penalties. The survey took approximately 45 minutes, and participants were prompted to e-mail their names to a separate email account to earn either extra credit in their course (if the instructor approved) or be entered into a drawing for cash prizes upon completion of the survey. To ensure confidentiality, the information provided by participants on the survey and their names submitted to the email account were not linked.

\section{Measures}

Demographics. Participants reported on demographic information about themselves and their parents, including their and each of their parent's age, gender, ethnicity, and country of birth. Participants also reported on their major and year in college.

Perceived parenting styles. The Parenting Styles and Dimensions Questionnaire (PSDQ), adapted by Nelson and colleagues (2011) for emerging adults, was used to measure emerging adults’ perceptions of their parents’ authoritative and authoritarian parenting styles. Factor analysis conducted by Nelson et al. (2011) demonstrated that the adapted items tapped the same aspects of parenting as compared to the original items of the Robinson, Mandleco, Olsen, 
and Hart (1995) measure for younger children. Participants rated 41items, each on a 5-point Likert scale $(1=$ Never to $5=$ Always $)$ to tap the overall dimensions of parenting of authoritativeness (e.g., "My parents show respect for my opinions by encouraging me to express them”) and authoritarianism (e.g., "My parents use threats as punishment with little or no justification”). The Cronbach’s alphas for authoritativeness and authoritarianism in the present sample were .92 and .89 , respectively.

Self-regulation abilities. Participants’ self-regulation ability was assessed using the Short Self-regulation Questionnaire (SSRQ; Carey, Neal, \& Collins, 2004). The SSRQ is a 31item questionnaire based on the Self-Regulation Questionnaire (SRQ; Brown, Miller, \& Lawendowski, 1998), which has a single factor that represents the overall self-regulation capacity (Carey et al., 2004). Participants rated their agreement to each statement on a Likert scale (1 = Strongly Disagree to 5 = Strongly Agree). Sample items included: "I am able to resist temptation," "I get easily distracted from my plans” and “It's hard for me to notice when I've had enough (alcohol, food, sweets).” A total self-regulation score was created using the sum of all items. Previous studies have shown high reliability using the SSRQ (e.g., Neal \& Carey, 2007). The Cronbach’s alpha in this study was .93.

\section{Results}

PROCESS (Hayes, 2012) in SPSS (v.22) was used to test the hypotheses. Table 1 displays the group comparison and correlations among the primary variables between the two cultural groups. A series of analysis of covariance (ANCOVA) were conducted to test the first hypothesis regarding the ethnic differences in parenting styles. Participants’ age, gender, maternal education and paternal education were entered as covariates. Results showed that Asian-American emerging adults reported receiving significantly lower levels of authoritative 
parenting, $F(1,371)=11.25, p=.001$, and higher levels of authoritarian parenting, $F(1,371)=$ 32.60, $p<.001$, compared to European-American emerging adults, as predicted. An ANCOVA used to test the second hypothesis regarding self-regulation differences between the two ethnic groups revealed that Asian-American emerging adults reported significantly lower levels of selfregulation ability than European-American emerging adults, $F(1,371)=6.47, p=.011$.

To test the third hypothesis, a moderated mediation analysis was performed using PROCESS model 74. Participants’ age, gender, maternal and paternal education were entered as the covariates, ethnicity was entered as the predictor and the moderator of the $b$ paths, the two parenting styles were entered as the mediators, and self-regulation was the outcome variable (Figure 1). Results indicated that participants’ ethnicity significantly predicted their selfregulation ability. Specifically, compared to European-American emerging adults, AsianAmerican emerging adults scored lower on self-regulation ability, $b=-0.15, S E=.06, t(371)=$ 2.54, $p=.011$. Results also showed that ethnicity significantly predicted parenting styles. Compared to European-Americans, Asian-Americans perceived receiving lower levels of authoritative parenting $[b=-0.29, S E=.09, t(371)=-3.35, p<.001]$ and higher levels of authoritarian parenting $[b=0.40, S E=.07, t(371)=5.71, p<.001]$. Authoritative parenting and authoritarian parenting each significantly predicted self-regulation ability for Asian-American [authoritative: $b=0.24, S E=.05, t(137)=5.27, p<.001$; authoritarian: $b=-0.12, S E=.06, t$ $(137)=2.07, p=.041]$ and European-American emerging adults [authoritative: $b=0.18, S E$ $=.05, t(224)=3.46, p<.001$; authoritarian: $b=-0.24, S E=.06, t(224)=-3.86, p<.001]$.After controlling for parenting styles, ethnicity no longer significantly predicted self-regulation, $b=$ $0.05, S E=.06, t(367)=-.85, p=.397$, indicating that ethnicity was only indirectly associated with self-regulation through parenting styles. Specifically, the indirect effect of ethnicity through 
authoritative parenting was -.05, 95\% CI [-0.10, -.02], and the indirect effect through authoritarian parenting was -.055, 95\% CI [-0.10, -.02].

The interactions “Ethnicity X Authoritative” $[b=0.11, S E=0.07, t(367)=1.47, p=.142]$ and "Ethnicity X Authoritarian" $[b=0.07, S E=0.09, t(367)=0.83, p=.406]$ were both nonsignificant, indicating that the effects of authoritative and authoritarian parenting styles on selfregulation among Asian-American and European-American emerging adults were not statistically different, supporting our third hypothesis. This result showed that authoritative parenting was associated with higher levels of self-regulation whereas authoritarian parenting was associated with lower levels of self-regulation for both groups of emerging adults (Figure 1).

\section{Discussion}

We conducted level-oriented comparisons between Asian-American and EuropeanAmerican emerging adults’ perceived parenting styles and self-regulation. We also conducted a structure-oriented comparison to examine patterns of association between Asian-American and European-American emerging adults’ parenting styles and self-regulation, to reveal culturalspecific or -shared contextual relations between these variables beyond the magnitude of meanlevel differences (Betancourt \& Lopez, 1993).

As hypothesized, Asian-American emerging adults perceived receiving lower levels of authoritative and higher levels of authoritarian parenting compared to their European-American peers, which is in line with previous research conducted with adolescents (e.g., Dornbusch et al., 1987; Steinberg et al., 1992). Parenting styles are presumed to be relatively consistent across time and contexts (Holden \& Miller, 1999; Smetana, 1994); thus, it is not surprising that similar patterns of ethnic differences in parenting styles were also found for emerging adults across the two cultural groups in the current study. Moreover, authoritative parenting and authoritarian 
parenting were significantly and negatively correlated only for the European-American sample, $r$ $=-.41, p<.01$; the two parenting styles were not significantly correlated for the Asian-American sample, $r=-.06, p=.462$. This difference may indicate that parents of European-American emerging adults who had higher levels of authoritative parenting were less likely to use authoritarian parenting. In contrast, Asian-American parents' use of authoritative parenting was unrelated to their use of authoritarian parenting. Other studies with samples of Asian parents have also shown a lack of or weak correlation between authoritative and authoritarian parenting (e.g., Xu et al., 2005; Zhou et al., 2004). This suggests that the two parenting styles in Asian families may operate orthogonally. Recent studies with Asian-American adolescents and their parents indicate that Asian-American parenting can demonstrate characteristics from both positive parenting dimensions (e.g., warmth, inductive reasoning, parental monitoring) and negative parenting dimensions (e.g., parental hostility, shaming, punitive parenting) (Choi, Kim, Kim, Park, 2013; Kim, Wang, Orozco-Lapray, Shen, \& Murtuza, 2013).”

Few studies to date have compared self-regulation in emerging adults from AsianAmerican and European-American cultures. Our results showed that the Asian-American emerging adults reported lower levels of self-regulation abilities compared to their EuropeanAmerican peers. Importantly, the ethnic differences in self-regulation scores were explained by the different levels of parenting styles perceived by individuals, where Asian-American emerging adults perceived receiving lower levels of authoritative and higher levels of authoritarian parenting compared to their European-American peers. Specifically, our results indicated that for both Asian-American and European-American emerging adults, the positive effect of authoritative parenting on self-regulation is significant during emerging adulthood when individuals are seeking more autonomy but at the same time, need to remain connected with their 
parents (O’Connor et al., 1996). The characteristics of authoritative parenting enable parents to employ effective means of parenting practices to balance providing autonomy and delivering demands to emerging adults, and this balanced use of autonomy granting, firm demand, necessary parental guidance, and support may lead emerging adults of authoritative parents in both Asian-American and European-American cultures to develop higher self-regulation ability. On the contrary, authoritarian parenting was associated with poorer self-regulation abilities for emerging adults in both Asian-American and European-American cultures. During this unique developmental period, emerging adults are undergoing a variety of life transitions and facing numerous possibilities. Authoritarian parenting, characterized as low in warmth, may fail to provide support and guidance needed by emerging adults. Moreover, authoritarian parenting could undermine emerging adults' self-regulation through the use of hostile parental control and harsh criticism. This finding is in line with Sorkhabi’s (2005) proposition that despite mean-level differences in parenting styles found in cultures described as independence-focused versus interdependence-focused, authoritative parenting is associated with positive individual outcomes whereas authoritarian parenting has a negative impact on developmental outcomes across cultural groups. Our findings extend this work into the emerging adulthood period.

\section{Limitations and Future Directions}

Several limitations of the current study need to be noted. First, the cross-sectional design of the study precludes our ability to make causal inferences regarding the relations between the variables. Indeed, emerging adults with poorer self-regulatory abilities may evoke more authoritarian parenting as parents try to infuse more control in their offspring's lives, whereas emerging adults with better self-regulatory skills allow their parents to engage in more autonomy promoting and warm parenting (Nelson et al., 2011). Thus, longitudinal data are needed to better 
inform the causal relations between parenting styles and self-regulation among Asian-American and European-American emerging adults. Second, the current study used a convenience sample of college students. Thus, our findings may not be generalized to emerging adults not attending college. Future studies should include emerging adults who are not attending college to obtain a more representative sample. We also did not differentiate between subgroups of Asian American due to the limited sample size. Important variations between groups have been documented (Chung, 2001) and should be explored in future research.

Another limitation to note is the possible influence of participants' acculturation level on our results. Within the Asian-American sample, 63\% were born and raised in the U.S. Differences in acculturation levels among these participants and their non-U.S. born counterparts may lead to differences in parenting and self-regulation between the European Americans and Asian Americans as well as the associations between perceived parenting styles and selfregulation. Future studies should examine how the acculturation level of Asian-American emerging adults may influence their perception of parenting styles and the development of selfregulation abilities, as well as the relation between parenting styles and self-regulation.

Our findings should be interpreted in light of the limitation of self-reported data. Emerging adults' report of parenting style and self-regulation reflect their perceptions rather than the actual parenting styles. The use of single reporters may also inflate the association between parenting styles and self-regulation. Thus, future studies should consider multiple reporters or using direct observations of parenting and self-regulation.

Moreover, the self-regulation measure in the current study (i.e., SSR) only yielded an average score across all items. Future research should assess and compare subdimensions of selfacross cultural groups, which can further inform the role of culture in these processes. Finally, 
researchers should examine emerging adults’ outcomes related to self-regulatory skills, such as academic functioning (Zimmerman \& Kitsantas, 2014), interpersonal relationship (Tangney, Baumeister, \& Boone, 2004) and psychological well-being (Gross \& John, 2003), which can help elucidate the function of self-regulation across these two cultural groups.

\section{Conclusions}

Despite these limitations, the present study contributes to our understanding of parenting effects on self-regulation of Asian-American and European-American emerging adults. Our findings indicate that parenting styles may continue to be important for individuals' self-regulation development beyond adolescence. Most notably, despite the mean-level differences found in parenting styles and self-regulation, the structure-oriented comparisons shows similar patterns of associations between parenting styles and self-regulation across Asian-American and EuropeanAmerican cultures. Although studies have suggested that authoritative and authoritarian parenting in Asian culture may have different meanings in comparison to the Western culture and thereby lead to different child developmental outcomes (Chao, 1994; Chao, 2001), our results imply the function of these parenting styles in the context of self-regulation development seems to be similar for Asian-American and European-American cultural groups. Together, these findings indicate that, for both Asian-Americans and European-Americans, parenting remains an important aspect of individuals' self-regulatory development during emerging adulthood.

Programs that aim to promote emerging adults' positive development should consider the role of parents. Interventions can promote parents’ skills and abilities to help their emerging adults develop regulatory skills needed for adulthood through parents' engagement in warm, responsive, and supportive relationships, external controls and clear standards for behavior, while granting autonomy to their emerging adult children. In addition, programs can help parents reduce their 
engagement in controlling, punitive, and intrusive parenting, which may undermine emerging adults' ability to practice regulatory skills to meet situational demands. Our findings imply that enhancing emerging adults' self-regulation through promotion of authoritative parenting and reduction of authoritarian parenting could be effective for both Asian-American and EuropeanAmerican emerging adults. 


\section{References}

Arnett, J. J. (1994). Sensation seeking: A new conceptualization and a new scale. Personality and Individual Differences, 16(2), 289-296. doi: 10.1016/0191-8869(94)90165-1

Arnett, J. J. (2000). Emerging adulthood: A theory of development from the late teens through the twenties. American Psychologist, 55(5), 469-480. doi: 10.1037//0003-066X.55.5.469

Bachman, J. G., Johnston, L. D., O'Malley, P. M., \& Schulenberg, J. (1996). Transitions in drug use during late adolescence and young adulthood. In J. A. Graber, J. Brooks-Gunn, \& A. C. Petersen (Eds.), Transitions through adolescence: Interpersonal domains and context (pp. 111- t40). Mahwah, NJ: Erlbaum.

Baumrind, D. (1971). Current patterns of parental authority. Developmental Psychology, 4, 1103.

Baumrind, D. (1991). Parenting styles and adolescent development. The Encyclopedia of Adolescence, 2, 746-758.

Betancourt, H., \& López, S. R. (1993). The study of culture, ethnicity, and race in American psychology. American Psychologist, 48(6), 629-637.

Blair, C., \& Diamond, A. (2008). Biological processes in prevention and intervention: The promotion of self-regulation as a means of preventing school failure. Development and Psychopathology, 20(03), 899-911. doi: 10.1017/S0954579408000436

Bowers, E. P., Gestsdottir, S., Geldhof, G. J., Nikitin, J., von Eye, A., Reiser, M. Losoya, S. H., \& Guthrie, I. K. (2011). Developmental trajectories of intentional self regulation in adolescence: The role of parenting and implications for positive and problematic outcomes among diverse youth. Journal of Adolescence, 34(6), 1193-1206. doi:10.1016/j.adolescence.2011.07.006 
Bridgett, D. J., Burt, N. M., Edwards, E. S., \& Deater-Deckard, K. (2015). Intergenerational transmission of self-regulation: A multidisciplinary review and integrative conceptual framework. Psychological Bulletin, 141(3), 602-654. doi: 10.1037/a0038662

Brown, J. M. (1998). Self-regulation and the addictive behaviors. In W. R. Miller \& N. Heather (Eds.), Treating addictive behaviors (2nd ed., pp. 61-73). New York: Plenum.

Carey, K. B., Neal, D. J., \& Collins, S. E. (2004). A psychometric analysis of the self-regulation questionnaire. Addictive behaviors, 29(2), 253-260. doi: 10.1016/j.addbeh.2003.08.001

Chao, R. K. (1994). Beyond parental control and authoritarian parenting style: Understanding Chinese parenting through the cultural notion of training. Child Development, 65(4), 1111-1119. doi: 10.1111/j.1467-8624.1994.tb00806.x

Chao, R. K. (2001). Extending research on the consequences of parenting style for Chinese Americans and European Americans. Child Development, 72(6), 1832-1843. doi: 10.1111/1467-8624.00381

Cheung, R. Y., \& Park, I. J. (2010). Anger suppression, interdependent self-construal, and depression among Asian American and European American college students. Cultural Diversity and Ethnic Minority Psychology, 16(4), 517-525. doi: 10.1037/a0020655

Choi, Y., Kim, Y. S., Kim, S. Y., \& Park, I. J. (2013). Is Asian American parenting controlling and harsh? Empirical testing of relationships between Korean American and Western parenting measures. Asian American Journal of Psychology, 4(1), 19. doi: $10.1037 / \mathrm{a} 0031220$

Chung, R. H. (2001). Gender, ethnicity, and acculturation in intergenerational conflict of Asian American college students. Cultural Diversity and Ethnic Minority Psychology, 7(4), 376. doi: 10.1037//1099-9809.7.4.376 
Collins, W. A., Maccoby, E. E., Steinberg, L., Hetherington, E. M., \& Bornstein, M. H. (2000). Contemporary research on parenting: the case for nature and nurture. American Psychologist, 55(2), 218-232. doi: 10.1037/0003-066X.55.2.218

Darling, N., \& Steinberg, L. (1993). Parenting style as context: An integrative model. Psychological Bulletin, 113(3), 487-496. doi: 10.1037/0033-2909.113.3.487

Dornbusch, S. M., Ritter, P. L., Leiderman, P. H., Roberts, D. F., \& Fraleigh, M. J. (1987). The relation of parenting style to adolescent school performance. Child Development, 12441257. doi: $10.2307 / 1130618$

Eiden, R. D., Colder, C., Edwards, E. P., \& Leonard, K. E. (2009). A longitudinal study of social competence among children of alcoholic and nonalcoholic parents: Role of parental psychopathology, parental warmth, and self-regulation. Psychology of Addictive Behaviors, 23(1), 36-46. doi: 10.1037/a0014839

Eisenberg, N., Zhou, Q., Spinrad, T. L., Valiente, C., Fabes, R. A., \& Liew, J. (2005). Relations among positive parenting, children's effortful control, and externalizing problems: A three-wave longitudinal study. Child Development, 76(5), 1055-1071. doi: 10.1111/j.1467-8624.2005.00897.x

Grolnick, W. S., \& Farkas, M. (2002). Parenting and the development of children’s selfregulation. Handbook of Parenting, 5, 89-110.

Grolnick, W. S., McMenamy, J. M., \& Kurowski, C. O. (1999). Emotional self regulation in infancy and toddlerhood. In L. Balter \& C.S. Tamis-LeMonda (Eds.), Child psychology: A handbook of contemporary issues (pp. 3-22). Ann Arbor, MI: Psychology Press. 
Grolnick, W. S., \& Ryan, R. M. (1989). Parent styles associated with children's self-regulation and competence in school. Journal of Educational Psychology, 81(2), 143-154. doi: 10.1037/0022-0663.81.2.143

Gross, J. J., \& John, O. P. (2003). Individual differences in two emotion regulation processes: implications for affect, relationships, and well-being. Journal of personality and social psychology, 85(2), 348.

Grusec, J. E., \& Goodnow, J. J. (1994). Impact of parental discipline methods on the child's internalization of values: A reconceptualization of current points of view. Developmental Psychology, 30(1), 4-19. doi: 10.1037/0012-1649.30.1.4

Hayes, A. F. (2012). PROCESS: A versatile computational tool for observed variable mediation, mod- eration, and conditional process modeling [White paper]. Retrieved from http://www.afhayes.com/ public/process2012.pdf

Holden, G. W., \& Miller, P. C. (1999). Enduring and different: A meta-analysis of the similarity in parents' child rearing. Psychological Bulletin, 125(2), 223-254.

IBM Corp. Released 2013. IBM SPSS Statistics for Windows, Version 22.0. Armonk, NY: IBM Corp

Karreman, A., van Tuijl, C., van Aken, M. A., \& Deković, M. (2006). Parenting and selfregulation in preschoolers: a meta-analysis. Infant and Child Development, 15(6), 561579. doi: 10.1002/icd.478

Kim, S. Y., Wang, Y., Orozco-Lapray, D., Shen, Y., \& Murtuza, M. (2013). Does “tiger parenting” exist? Parenting profiles of Chinese Americans and adolescent developmental outcomes. Asian American Journal of Psychology, 4(1), 7. doi: 10.1037/a0030612 
Kitsantas, A., Winsler, A., \& Huie, F. (2008). Self-regulation and ability predictors of academic success during college: A predictive validity study. Journal of Advanced Academics, 20(1), 42-68.

Kochanska, G., \& Aksan, N. (1995). Mother-child mutually positive affect, the quality of child compliance to requests and prohibitions, and maternal control as correlates of early internalization. Child Development, 66(1), 236-254.

Kochanska, G., \& Knaack, A. (2003). Effortful control as a personality characteristic of young children: Antecedents, correlates, and consequences. Journal of personality, 71(6), 10871112. doi: $10.1111 / 1467-6494.7106008$

Leung, K., Lau, S., \& Lam, W. L. (1998). Parenting styles and academic achievement: A crosscultural study. Merrill-Palmer Quarterly (1982-), 157-172.

Li, Y., Costanzo, P. R., \& Putallaz, M. (2010). Maternal socialization goals, parenting styles, and social-emotional adjustment among Chinese and European American young adults: Testing a mediation model. The Journal of Genetic Psychology, 171(4), 330-362. doi: $10.1080 / 00221325.2010 .505969$

Lindahl, K. M., \& Malik, N. M. (1999). Marital conflict, family processes, and boys' externalizing behavior in Hispanic American and European American families. Journal of Clinical Child Psychology, 28(1), 12-24. doi: 10.1207/s15374424jccp2801_2

Maccoby, E. E., \& Martin, J. A. (1983). Socialization in the context of the family: Parent-child interaction. Handbook of Child Psychology: Formerly Carmichael's Manual of Child Psychology/Paul H. Mussen, editor. 
McClelland, M. M., Acock, A. C., Piccinin, A., Rhea, S. A., \& Stallings, M. C. (2013). Relations between preschool attention span-persistence and age 25 educational outcomes. Early Childhood Research Quarterly, 28(2), 314-324. doi: 10.1016/j.ecresq.2012.07.008

McClelland, M. M., \& Wanless, S. B. (2012). Growing up with assets and risks: The importance of self-regulation for academic achievement. Research in Human Development, 9(4), 278-297. doi: 10.1080/15427609.2012.729907

Moffitt, T. E., Arseneault, L., Belsky, D., Dickson, N., Hancox, R. J., Harrington, H., Houts, R., Poulton, R., Roberts, B.W., Ross, S., \& Sears, M. R. (2011). A gradient of childhood self-control predicts health, wealth, and public safety. Proceedings of the National Academy of Sciences, 108(7), 2693-2698.

Moilanen, K. L., Rasmussen, K. E., \& Padilla-Walker, L. M. (2015). Bidirectional associations between self-regulation and parenting styles in early adolescence. Journal of Research on Adolescence, 25(2), 246-262. doi: 10.1111/jora.12125

Neal, D. J., \& Carey, K. B. (2005). A follow-up psychometric analysis of the self-regulation questionnaire. Psychology of Addictive Behaviors, 19(4), 414-422. doi: 10.1037/0893164X.19.4.414

Neal, D. J., \& Carey, K. B. (2007). Association between alcohol intoxication and alcohol-related problems: An event-level analysis. Psychology of Addictive Behaviors, 21(2), 194-204. doi: 10.1037/0893-164X.21.2.194

Nelson, L. J., Padilla-Walker, L. M., Christensen, K. J., Evans, C. A., \& Carroll, J. S. (2011). Parenting in emerging adulthood: An examination of parenting clusters and correlates. Journal of Youth and Adolescence, 40(6), 730-743. doi:10.1007/s10964-010-9584-8 
Niemiec, C. P., Lynch, M. F., Vansteenkiste, M., Bernstein, J., Deci, E. L., \& Ryan, R. M. (2006). The antecedents and consequences of autonomous self-regulation for college: A self-determination theory perspective on socialization. Journal of Adolescence, 29(5), 761-775. doi: 10.1016/j.adolescence.2005.11.009

O'Connor, T. G., Allen, J. P., Bell, K. L., \& Hauser, S. T. (1996). Adolescent-parent relationships and leaving home in young adulthood. New Directions for Child and Adolescent Development, 1996(71), 39-52. doi: 10.1002/cd.23219967105

Patock-Peckham, J. A., Cheong, J., Balhorn, M. E., \& Nagoshi, C. T. (2001). A social learning perspective: a model of parenting styles, self-regulation, perceived drinking control, and alcohol Use and problems. Alcoholism: Clinical and Experimental Research, 25(9), 1284-1292. doi: 10.1111/j.1530-0277.2001.tb02349.x

Petanjek, Z., Judaš, M., Kostović, I., \& Uylings, H. B. (2008). Lifespan alterations of basal dendritic trees of pyramidal neurons in the human prefrontal cortex: a layer-specific pattern. Cerebral Cortex, 18(4), 915-929. doi: 10.1093/cercor/bhm124

Pinquart, M., \& Kauser, R. (2017). Do the Associations of Parenting Styles With Behavior Problems and Academic Achievement Vary by Culture? Results from a Meta-Analysis. Cultural Diversity and Ethnic Minority Psychology, doi: 10.1037/cdp0000149

Pong, S. L., Hao, L., \& Gardner, E. (2005). The roles of parenting styles and social capital in the school performance of immigrant Asian and Hispanic adolescents. Social Science Quarterly, 86(4), 928-950. doi: 10.1111/j.0038-4941.2005.00364.x

Pong, S. L., Johnston, J., \& Chen, V. (2010). Authoritarian parenting and Asian adolescent school performance: Insights from the US and Taiwan. International journal of behavioral development, 34(1), 62-72. doi: 10.1177/0165025409345073 
Putnam, S. P., Spritz, B. L., \& Stifter, C. A. (2002). Mother-Child Coregulation During Delay of Gratification at 30 Months. Infancy, 3(2), 209-225. doi: 10.1207/S15327078IN0302_6

Robinson, C. C., Mandleco, B., Olsen, S. F., \& Hart, C. H. (1995). Authoritative, authoritarian, and permissive parenting practices: Development of a new measure. Psychological Reports, 77(3), 819-830.

Rossier, J., Dahourou, D., \& McCrae, R. R. (2005). Structural and mean-level analyses of the five-factor model and locus of control: Further evidence from Africa. Journal of CrossCultural Psychology, 36(2), 227-246.

Smetana, J. G. (1994). Parenting styles and beliefs about parental authority. New Directions for Child and Adolescent Development, 1994(66), 21-36. doi: 10.1002/cd.23219946604

Smith, P. B., \& Bond, M. H. (2003). Honoring culture scientifically when doing social psychology. In M. A. Hogg \& J. Cooper (Eds.), The SAGE handbook of social psychology, 43-61.

Sorkhabi, N. (2005). Applicability of Baumrind's parent typology to collective cultures: Analysis of cultural explanations of parent socialization effects. International Journal of Behavioral Development, 29(6), 552-563. doi: 10.1080/01650250500172640

Spinrad, T. L., Eisenberg, N., Cumberland, A., Fabes, R. A., Valiente, C., Shepard, S. A., Reiser, M., Losoya, S. H., \& Guthrie, I. K. (2006). Relation of emotion-related regulation to children's social competence: a longitudinal study. Emotion, 6(3), 498-510. doi: 10.1037/1528-3542.6.3.498

Steinberg, L. (2004). Risk taking in adolescence: what changes, and why? Annals of the New York Academy of Sciences, 1021(1), 51-58. doi: 10.1196/annals.1308.005 
Steinberg, L., Dornbusch, S. M., \& Brown, B. B. (1992). Ethnic differences in adolescent achievement: An ecological perspective. American Psychologist, 47(6), 723-729. doi: 10.1037/0003-066X.47.6.723

Tangney, J. P., Baumeister, R. F., \& Boone, A. L. (2004). High self-control predicts good adjustment, less pathology, better grades, and interpersonal success. Journal of personality, 72(2), 271-324.

Trommsdorff, G. (2009). Culture and development of self-regulation. Social and Personality Psychology Compass, 3(5), 687-701. doi: 10.1111/j.1751-9004.2009.00209.x

Trommsdorff, G. (2012). Development of “agentic” regulation in cultural context: the role of self and world views. Child Development Perspectives, 6(1), 19-26. doi: 10.1111/j.17508606.2011.00224.x

Van de Vijver, F. J., \& Leung, K. (1997a). Methods and data analysis for cross-cultural research (Vol. 1). Sage.

Van de Vijver, F. J., \& Leung, K. (1997b). Methods and data analysis of comparative research. In J. W. Berry, Y. H. Poortinga, \& J. Pandey (Eds.), Handbook of Cross-cultural Psychology. Vol. 1: Theory and method (pp. 257-300). Boston: Allyn \& Bacon.

Vansteenkiste, M., Simons, J., Lens, W., Sheldon, K. M., \& Deci, E. L. (2004). Motivating learning, performance, and persistence: the synergistic effects of intrinsic goal contents and autonomy-supportive contexts. Journal of Personality and Social Psychology, 87(2), 246-260. doi: 10.1037/0022-3514.87.2.246

Wrosch, C., Scheier, M. F., Miller, G. E., Schulz, R., \& Carver, C. S. (2003). Adaptive selfregulation of unattainable goals: Goal disengagement, goal reengagement, and subjective 
well-being. Personality and Social Psychology Bulletin, 29(12), 1494-1508. doi: $10.1177 / 0146167203256921$

Xu, Y., Farver, J. A., Zhang, Z., Zeng, Q., Yu, L., \& Cai, B. (2005). Mainland Chinese parenting styles and parent-child interaction. International Journal of Behavioral Development, 29(6), 524-531. doi : 10.1080/01650250500147121

Zeidner, M., Boekaerts, M., \& Pintrich, P. R. (1999). Self-regulation. Handbook of selfregulation.

Zhou, Q., Eisenberg, N., Wang, Y., \& Reiser, M. (2004). Chinese children's effortful control and dispositional anger/frustration: relations to parenting styles and children's social functioning. Developmental Psychology, 40(3), 352-366. doi: 10.1037/00121649.40.3.352

Zimmerman, B. J., \& Kitsantas, A. (2014). Comparing students' self-discipline and selfregulation measures and their prediction of academic achievement. Contemporary Educational Psychology, 39(2), 145-155. doi: 10.1016/j.cedpsych.2014.03.004 